\title{
Sıcak Plaka Kaynak Yöntemi ile Birleştirilmiş Benzer ve Benzer Olmayan Alçak Yoğunluklu Polietilen (AYPE) Bağlantıların Mekanik Özelliklerinin Karşılaştırmalı Olarak Araştırılması
}

\section{Comparative Investigation of Mechanical Properties of Similar and Dissimilar Low Density Polyethylene (LDPE) Welds Joined with Hot Plate Welding Method}

\section{Nahit Öztoprak *}

Dokuz Eylül Üniversitesi, Mühendislik Fakültesi, Makine Mühendisliği Bölümü, İzmir, TÜRKIYE Sorumlu Yazar / Corresponding Author*: nahit.oztoprak@deu.edu.tr

\author{
Geliș Tarihi / Received: 04.03.2020 Araștırma Makalesi/Research Article \\ Kabul Tarihi / Accepted: 24.04.2020 DOI:10.21205/deufmd.2020226620 \\ Atıf șekli/How to cite: OZTOPRAK, N., (2020). Sicak Plaka Kaynak Yöntemi ile Birleștirilmiş Benzer ve Benzer Olmayan Alçak Yoğunluklu \\ Polietilen (AYPE) Bağlantıların Mekanik Özelliklerinin Karşılaştırmalı Olarak Araştırılması. DEUFMD 22(66), 861-874.
}

\section{Özet}

Polimerlerin kullanımıyla ilgili endüstriyel talepler ve dolayısıyla daha güvenilir birleștirme teknikleri arayışı giderek artmaktadır. Termoplastikleri birleştirmek için en basit ve ekonomik yöntemlerden biri olan Sıcak Plaka Kaynağı (SPK) kullanımının güçlü bağlantılar ürettiği bilinmektedir. Bu çalışma, Alçak Yoğunluklu Polietilen (AYPE) malzeme ile Yüksek Yoğunluklu Polietilen (YYPE) malzemenin uygun parametreler eşliğinde SPK yöntemi kullanılarak, güvenilir biçimde birleștirilmesinin mümkün olduğunu ortaya koymaktadır. Araștırmada, benzer ve farklı polietilen sınıfları birbirleri ile birleştirilerek, bağlantıların mekanik özellikleri, çekme dayanımı ve çarpma davranışları açısından incelenmiştir. Elde edilen sonuçlar ana malzemeler ve bağlantıların kendi arasında karşılaștırılmıștır. Çekme deneyleri sonrası bağlantıların kırılma yüzeyleri de irdelenmiştir. Buna göre, AYPE malzemeler YYPE malzemeler ile birleștirilerek, AYPE malzemelerin kendi aralarındaki kaynak ișlemine göre daha üstün çekme dayanımı ve șekil değiștirme davranıșı elde edilmiştir. İlaveten, benzer olmayan kaynak bağlantılarında benzer bağlantılara göre çarpma enerjisinin büyük ölçüde arttığı belirlenmiştir.

Anahtar Kelimeler: Sıcak plaka kaynağı, Düşük yoğunluklu polietilen, Yüksek yoğunluklu polietilen, Mekanik özellikler

\begin{abstract}
Industrial demands of utilizing polymers and therefore, the search for more reliable joining techniques is gradually increasing. The use of Hot Plate Welding (HPW), which is one of the simplest and most economical methods of joining thermoplastics, is known to manufacture strong joints. This study reveals that it is possible to join LDPE and HDPE snugly using HPW method with appropriate parameters. In the research, similar and dissimilar polyethylene classes are joined with each other and mechanical properties of the joints are examined in terms of the tensile strength and impact behaviors. Obtained results are compared considering the base materials themselves and between
\end{abstract}


DEÜ FMD 22(66), 861-874, 2020

the joints. After the tensile tests, fracture surfaces of the joints are also scrutinized. Accordingly, LDPE are joined with HDPE, resulting in superior tensile strength and deformation behavior compared to the welding process of LDPE materials among themselves. Additionally, it has been reported that the impact energy significantly increases in dissimilar welds in comparison to the similar welds.

Keywords: Hot plate welding, Low-density polyethylene, High-density polyethylene, Mechanical properties

\section{Giriș}

Günümüz malzeme teknolojisindeki ilerlemeler ve artan endüstriyel talep ile birlikte polimerik malzemelere olan ilgi artmaktadır. Plastikler, çelik ve demir dişı malzemeler ile karșılaștırıldıklarında, düșük maliyetleri ve endüstrinin farklı alanlarındaki mühendislik uygulamaları için daha elverișli olmaları nedeniyle siklıkla tercih edilmektedirler. Ambalaj sanayinden otomotive kadar yaygın bir kullanım alanları mevcuttur [1]. Plastikler içerisinde termoplastik polimerler özellikle otomotiv ve havacılık sanayilerinde üstün isıl yalıtım özellikleri, ağırlık azaltımı sağlamaları ve üretim maliyetlerindeki düşüklük nedeniyle metalik malzemelerin yerini almaktadırlar. $\mathrm{Bu}$ avantajlarının yanında, yeniden isitılabilme, yeniden biçimlendirilebilme, geri kazanılabilirlik, üst seviye yorulma direnci ve kırılma tokluğuna sahip olma gibi öne çlkan özellikleri sebebiyle de termosetler ve elastomerler ile karşılaștırıldığında en yaygın kullanım alanına sahip olan polimer çeşididirler $[2,3]$. Polietilenler ise sağlamlık, esneklik, yüksek darbe dayanımı ve uygun kimyasal direnç özellikleri ile dikkati çeken en yaygın kullanım alanına sahip poliolefin termoplastiklerdendir [4,5]. Aynı zamanda düșük maliyetli olan bu polimerler, yoğunluk ve sonucundaki özellik değişimleri nedeniyle düşük yoğunluklu polietilen, doğrusal düșük yoğunluklu polietilen ve yüksek yoğunluklu polietilen şeklinde üretilebilmekte ve sinıflandırılmaktadırlar [6,7].

Düşük yoğunluklu polietilen hafif ağırlı̆̆l, yüksek kimyasal dayanımı, üretim sürecindeki kolaylığı ve en önemlisi ucuz bir polimer türü olması gibi cazip özellikleri nedeniyle geniş endüstriyel kullanım alanına sahiptir [8-10]. Yarı kristal $(\sim 40 \%)$ bir polimer olan bu malzemenin çok çeșitli endüstriyel uygulama alanları bulunmaktadır [11]. Geri dönüșümlü olma özelliği, bu polimer sınıfının paketlemeden, su yalıtımı veya korozyon direnci istenen uygulamalara kadar kullanımını mümkün kılmaktadır [12]. Öte yandan, yüksek yoğunluklu polietilen diğer polietilen sınıflarına göre nispeten yüksek ergime sıcaklığı ve daha dengeli mekanik özellikleri sebebiyle, ısıl ve mekanik mühendislik uygulamalarında sıklıkla tercih edilmektedir $[13,14]$. Yüksek süneklik, yüksek tokluk, üstün kimyasal ve çevresel dayanıklılık özellikleri bu malzemelerin otomotiv parçalarından boru hatlarına, paketlemeden denizcilik sektöründe kullanımına kadar geniş ve yaygın uygulama alanlarının önünü açmıştır [15-18].

Polietilenlerin mühendislik uygulamalarındaki artan kullanımı, bu malzemelerin kendi aralarında ve farklı polietilen sınıfları ile güvenilir biçimde birleştirilme ihtiyacını ortaya çlkarmaktadır. Mekanik bağlantı, yapıșkanlı birleştirme ve direkt birleștirme yöntemleri termoplastik malzemelerin bilinen birleştirme teknikleridir. Direkt birleştirme yöntemlerinden biri olan Sıcak Plaka Kaynağı (SPK), basit ve ekonomik oluşu nedeniyle diğer yöntemler arasında oldukça ilgi çekmektedir [2]. Sahip olduğu potansiyel bu yöntemin araç arka lambalarından, akü kutularına, yakıt tanklarından gaz veya sıvı iletim hatlarındaki borulara kadar uygulama alanı bulmasını sağlamıștır [19-21]. Bu yöntem genel olarak sırasıyla ısıtma, birleştirme ve soğutma aşamalarından oluşmaktadır. Kaynaklanacak parçaların yüzeyi politetrafloretilen kaplı ısıtma elemanı ile tam olarak veya bazı durumlarda kısmen ergimenin sağlanması için temas ettirilir. Kaynak süresince uygun basınç değerleri ile kaynaklanacak parçalar ve sıcak levha arasındaki temasın sürekliliği sağlanır. Bu noktada, uygulanan basıncın aşırı veya çok az olmaması kaynak dayanımı açısından önemlidir. Son olarak, malzeme yumuşaması ve akışının görülmesi ile beraber sıcak plaka kaldırılır ve ergimiş yüzeyler sağlıklı bir birleşme sağlanıncaya kadar birbirlerine doğru bastırılır [22]. Isıtma plakasının sıcaklığı, ısıtma süresi, kaynak süresi ve birleștirme işlemi esnasındaki 
DEÜ FMD 22(66), 861-874, 2020

basınc bu tekniğin temel değișkenleri olarak bilinmektedir $\quad[23,24]$. Kaynaklanacak malzemelerin ergime noktası başarılı bir kaynak işlemi için oldukça önemli bir parametredir [25].

Termoplastik malzemelerin sıcak plaka kaynağ ile birleştirme işlemine yönelik bugüne kadar yapılan çalışmalar incelendiğinde, araştırmaların çoğunlukla benzer polimerlerin veya polimer matris kompozitlerin kaynağına odaklandığı görülmüștür [26-30]. Hâlbuki mühendislik uygulamalarında benzer olmayan malzemelerin yaygın biçimde ortak kullanımları mevcuttur. Ayrica, benzer olmayan malzemelerin birleştirilmesi, sadece parçanın önemli kısmında daha üstün ve daha güvenli malzemenin kullanımına olanak sağlaması ve böylece parça üretim maliyetini azaltması nedeniyle günümüzde oldukça popüler bir uygulama haline gelmiștir [31]. Bu çalıșmada, AYPE malzemeler kendi aralarında ve YYPE malzemeler ile SPK tekniği kullanılarak birleștirilmiş, elde edilen bağlantıların mekanik özellikleri ana malzemelere göre ve bağlantıların kendi aralarında karşılaştırmalı olarak incelenmiștir. Cekme testi sonrası kırılma yüzeyleri de taramalı elektron mikroskobu aracılığıyla değerlendirilmiștir. Elde edilen sonuçlara göre, çekme dayanımı ve çarpma davranışı açısından kaynaklı benzer bağlantılara kıyasla daha iyi mekanik özelliklere sahip bağlantılar elde edilmiştir.

\section{Malzeme ve Yöntem}

\subsection{Malzemeler}

Bu çalışmada, teknik özellikleri sırasıyla Tablo 1 ve Tablo 2'de verilen PETKIM Petrokimya Holding A.Ş. ürünleri AYPE (PETILEN G03-5) ve YYPE (PETILEN YY I668) termoplastik malzemeler kullanılmıștır. Söz konusu ürünlerden özel kalıplar kullanılarak, TS EN ISO 294-1 "Plastikler-Termoplastik malzemelerden enjeksiyon kalıplama ile deney parçalarının hazırlanması-Bölüm 1: Genel prensipler ve çok amaçlı çubuk deney parçalarının kalıplanması" [32] standardına uygun ana malzeme çekme test ve Sicak Plaka Kaynak (SPK) numuneleri Dr BOY 50T enjeksiyon kalıplama makinesi aracılığıyla üretilmiştir. Numune üretiminde kullanılan enjeksiyon makinesi Şekil 1'de gösterilmektedir.

\subsection{Sıcak plaka kaynağı}

Benzer ve benzer olmayan polietilen sınıflarının SPK yöntemi ile birleștirilmesi sonrası bağlantıların mekanik özelliklerinin incelendiği bu çalışmada, kaynak işlemleri, sabit basınç temelinde pozisyon kontrol prensibine göre Tablo 3'de verilen parametreler kullanılarak gerçekleștirilmiștir. Söz konusu parametreler, araştırma öncesi yapılan deneysel ön çalışmalar ve malzemelerin kristalleşme sıcaklıkları göz önünde bulundurularak belirlenmiștir [33]. Üç ana düzeneğin bir araya gelmesi ile oluşan sistemde, ısıtma plakası düzeneği, birbirlerinden bağımsız olarak farklı plaka sıcaklıklarını elde etme imkânı oluşturması sebebiyle özellikle farklı malzemelerin birleştirme işleminin yapılabilmesini sağlamaktadır. Pnömatik hareket düzeneği, numunelerin sicak eleman ile bir araya getirilmesi, ergitme işlemi sonrası sıcak elemandan uzaklaştırılması ve kaynak işlemi için malzemelerin alın alına getirilmesi noktasında kullanılmaktadır. Son olarak kumanda kutusu (kontrol ünitesi) da, kaynak parametrelerini düzenlemenin yanında, pistonlar ve sıcak elemanların kontrolünü sağlamaktadır. Şekil 2 SPK makine tertibatını ve çalışma prensibini şematik olarak göstermektedir. Birleştirilecek numune boyutları da Şekil 3'de verilmiștir. 
DEÜ FMD 22(66), 861-874, 2020

Tablo 1. AYPE ürün teknik özellikleri [34]

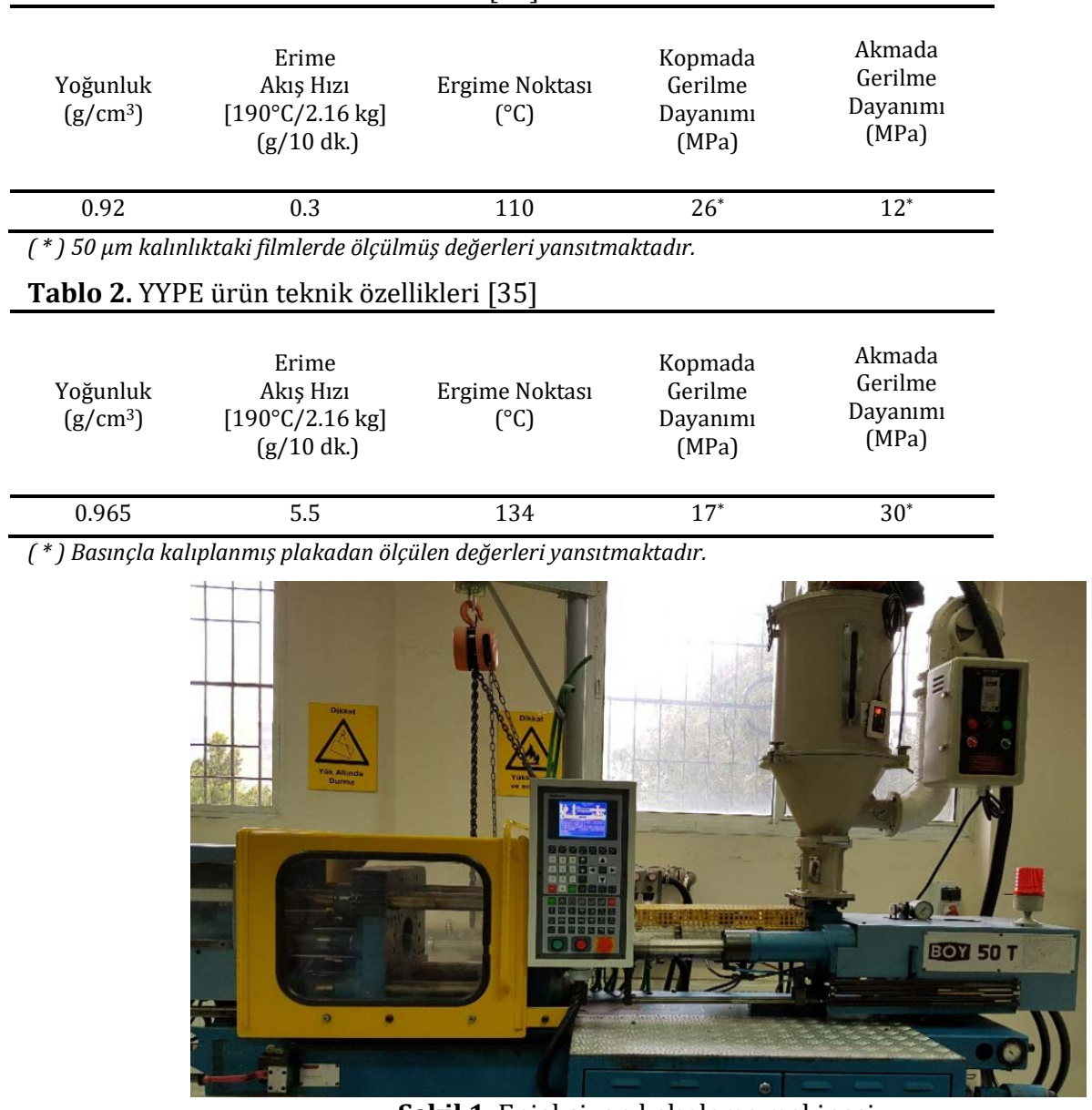

Şekil 1. Enjeksiyon kalıplama makinesi

Tablo 3. SPK parametreleri

\begin{tabular}{|c|c|c|c|c|c|c|}
\hline \#Bağlantı & \#Malzemeler & $\begin{array}{c}\text { \#Plaka Sicaklığı } \\
\left({ }^{\circ} \mathbf{C}\right)\end{array}$ & $\begin{array}{c}\text { \#Isıtma Süresi } \\
\mathbf{( s )}\end{array}$ & $\begin{array}{c}\text { \#Kaynak } \\
\text { Mesafesi } \\
(\mathbf{m m})\end{array}$ & $\begin{array}{c}\text { \#Kaynak } \\
\text { Zamanı } \\
(\mathbf{s})\end{array}$ & $\begin{array}{c}\text { \#Çalışma } \\
\text { Basıncı } \\
\text { (Bar) }\end{array}$ \\
\hline AA & AYPE-AYPE & $220-220$ & $25-25$ & 1.5 & 45 & 3.3 \\
\hline AY & AYPE-YYPE & $220-235$ & $25-25$ & 1.5 & 45 & 3.3 \\
\hline
\end{tabular}


DEÜ FMD 22(66), 861-874, 2020

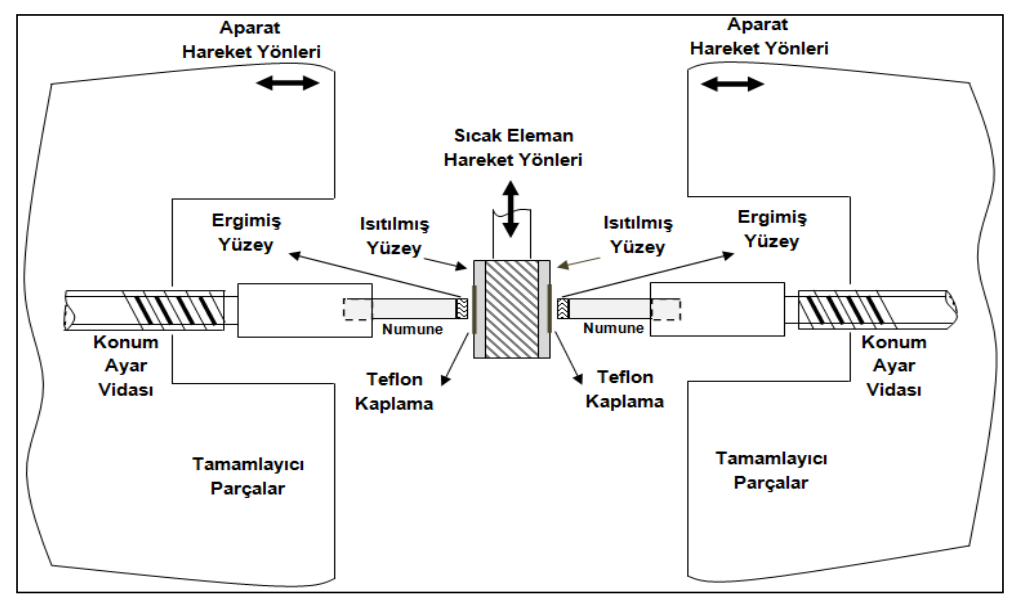

Şekil 2. SPK makinesi şematik çizimi ve çalışma prensibi

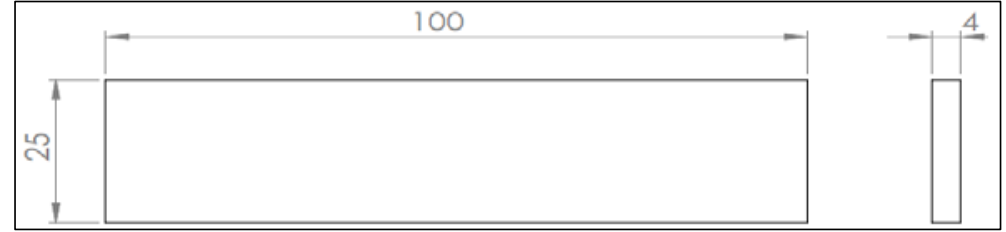

Şekil 3. SPK yöntemi ile birleştirilecek numune boyutları

\subsection{Kaynaklı numunelerin çekme testi}

Kaynaklı bağlantıların dayanımını belirleyebilmek için numunelere, Shimadzu AG$\mathrm{X}(100 \mathrm{kN})$ deney cihazı kullanılarak TS EN 12814-2 standardına göre [36] $23 \pm 2{ }^{\circ} \mathrm{C}$ sıcaklıkta $5 \mathrm{~mm} / \mathrm{dk}$ hızda çekme testleri uygulanmıştır. Ana malzemelere ait kaynaksız çekme testi numuneleri de karşılaștırma için aynı koşullarda test edilmiştir. Şekil 4 ve Şekil 5 sırasıyla ana malzemelere ve kaynaklı bağlantılara ait çekme deney numunelerini ve ölçülerini göstermektedir. Her bir bağlantı çeșidi için 4 örnek teste tabi tutulmuştur (Şekil 6). Numuneler bağlantıların maksimum mukavemeti ve bu gerilme değeri altındaki yüzde uzaması açısından incelenmiș, karşılaştırma açısından 4 örnekten elde edilen ortalama değerler kullanılmıştır.

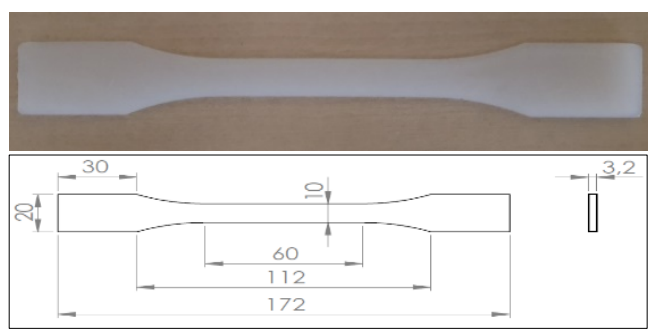

Şekil 4. Çekme testi numuneleri ve ölçüleri

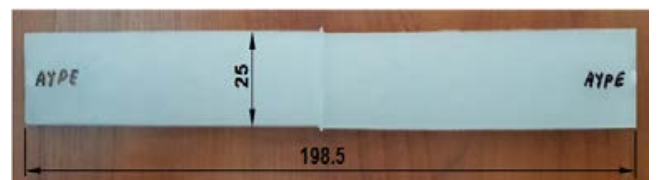

Şekil 5. Kaynaklı numuneler ve ölçüleri

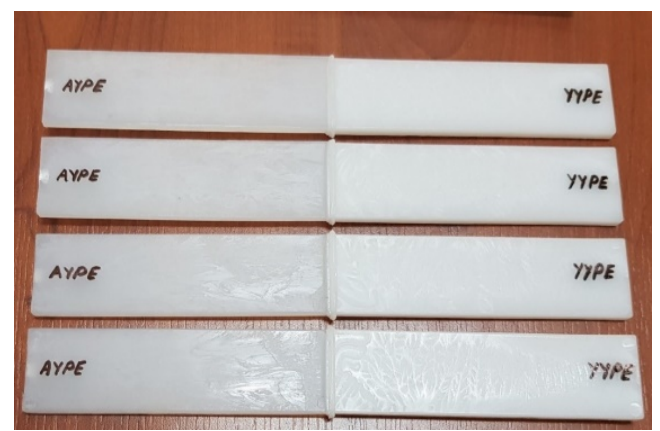

Şekil 6. AYPE-YYPE (AY) bağlantı numuneleri

2.4. Kaynaklı numunelerin çarpma deneyleri

Kaynaklı birleștirmelerin soğurduğu enerjiyi ve çarpma tokluğunu belirlemek için, Izod çentiksiz çarpma deneyleri gerçekleştirilmiştir. Testler ana malzemeler ile aynı koşullar dikkate alınarak uygulanmıştır. Gerilim yoğunlaştırıcı çentik istenmediğinden ve kaynaklı bağlantılardan çentikli numune oluşturmak doğru olmayacağından söz konusu yöntem 
seçilmiștir. Ana malzemeler için $100 \mathrm{~mm} \times 25$ $\mathrm{mm} \times 4 \mathrm{~mm}$ boyutlara sahip SPK numuneleri kullanılırken, kaynaklı numune boyutları çekme testindeki örnek boyutları ile aynıdır. Yapılan testler sonucunda, 4 numuneden elde edilen ortalama değer hesaplanmış ve karşılaştırma için kullanılmıștır. Ana malzemelere ve kaynaklı numunelere uygulanan çarpma deneyleri, Şekil7'de gösterilen sarkaç tipi çarpma test cihazı (maksimum enerji: 294.2 J, sarkaç etkili ağırlı̆̆ı: $18.75 \mathrm{~kg}$, dönme ekseninden numune merkezine uzaklık: $825 \mathrm{~mm}$, VEB Werkstoffprüfmaschinen Leipzig) yardımıyla oda sıcaklığında yapılmıştır.

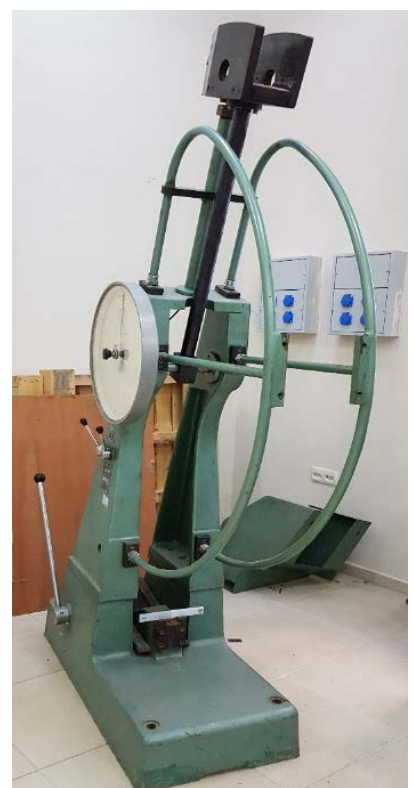

Şekil 7. Sarkaç tipi çarpma mukavemeti deney cihazı ve numune konumlanması

\section{Bulgular ve Tartışma}

\subsection{Cekme özellikleri}

AYPE ve YYPE ana malzemelerin maksimum çekme dayanımı, yüzde uzama değerleri sırasıyla $12.60 \mathrm{MPa}$ \%65.60 ve $22.07 \mathrm{MPa}$, $\%$ olarak elde edilmiștir. Cekme deneylerine ait sonuçlar Tablo 4'de verilmiștir. Söz konusu testler sonucunda elde edilen gerilim-gerinim eğrileri de Sekil 8 ve Sekil 9'da gösterilmektedir. Beklenildiği gibi, AYPE malzemelerin daha düșük mukavemet ve hasar anında uzama değerlerine sahip olduğu belirlenmiștir. Öte yandan, YYPE malzemelerin de maksimum gerilme altındaki boyca uzamasının AYPE numunelere göre oldukça düşük olduğu tespit edilmiştir. Bu noktada, YYPE malzemelerin birim şekil değiştirme değerinin $\sim \% 700$ ve daha fazla olması, bu değerlerin de çekme cihazı tarafından doğru şekilde ölçülemeyeceğinin bilinmesinden dolayı, malzeme elastik bölge sonrası maksimum gerilme değerine ulaşıp ölçüm boyu içerisinden boyun vermeye başladıktan belli bir uzama sonrası testler sonlandırılmıştır [37]. Şekil 9 içerisinde gösterilen oklar her bir numunenin şekil değişiminin devam ettiğini ifade etmektedir.

Benzer (AA) ve benzer olmayan (AY) bağlantılara ait gerilme-gerinim eğrileri sırasıyla Şekil 10 ve Şekil 11'de verilmiștir. Buna göre, AA bağlantıların ana malzemelerden (AYPE) farklı biçimde gevrek bir davranış göstererek, maksimum gerilme altında daha düşük şekil değiștirme değerlerinde hasara uğradığı gözlemlenmiştir. AA bağlantıların hepsi kaynak bölgesinden hasara uğramıștır. Numunelerin hasar bölgeleri Şekil 12'de verilmiştir. Diğer taraftan, AY bağlantıların çekme davranışları AYPE ana malzeme çekme davranıșı ile benzerlik göstermektedir. $\mathrm{Bu}$ duruma sebep olarak AY bağlantıların daha düşük mukavemet özelliklerine sahip ana malzemeden (AYPE) boyun vererek kaynak bölgesi dışından hasara uğraması gösterilebilir (Şekil 13). AY bağlantılarda, test numunelerinden sadece bir tanesi kaynak bölgesinden hasara uğramıștır. Şekil 14 numunelerin hasar bölgelerini göstermektedir. Benzer malzemelerin kaynak ișlemi sonrası mekanik davranıșı ile karșılaștırıldığında, AY bağlantıların AA bağlantılardan farklı olarak viskoelastik așama, viskoelastik ve viskoplastik aşamalar arasında gerilme platosu benzeri bir geçiș bölgesi ve șekil değiștirme sertleșmesi ile devam eden bir viskoplastik davranışa sahip oldukları belirlenmiștir [38]. Bunun yanında, AY bağlantıların çekme özelliklerinin birbirlerine çok yakın olması, SPK işlemi sonrası benzer olmayan birleştirmelerin çekme davranışının tekrarlanabilirliğini açıkça ortaya koymaktadır. 
DEÜ FMD 22(66), 861-874, 2020

Tablo 4. AYPE ve YYPE ana malzemelerin çekme deneyi sonuçları

\begin{tabular}{|c|c|c|c|c|c|c|}
\hline Numune & & 1 & 2 & 3 & 4 & Ortalama Değer \\
\hline \multirow[t]{2}{*}{ AYPE } & $\begin{array}{c}\text { Azami } \\
\text { Çekme Mukavemeti } \\
\text { (MPa) }\end{array}$ & 12.50 & 12.40 & 12.73 & 12.76 & 12.60 \\
\hline & $\begin{array}{c}\text { Azami Gerilme Altında } \\
\text { Boyca Uzama } \\
(\%)\end{array}$ & 60.65 & 70.42 & 68.04 & 63.27 & 65.60 \\
\hline \multirow[t]{2}{*}{ YYPE } & $\begin{array}{c}\text { Azami } \\
\text { Çekme Mukavemeti } \\
\text { (MPa) }\end{array}$ & 22.47 & 22.31 & 22.73 & 20.75 & 22.07 \\
\hline & $\begin{array}{c}\text { Azami Gerilme Altında } \\
\text { Boyca Uzama } \\
(\%)\end{array}$ & 9.52 & 8.80 & 6.82 & 7.27 & 8.10 \\
\hline
\end{tabular}

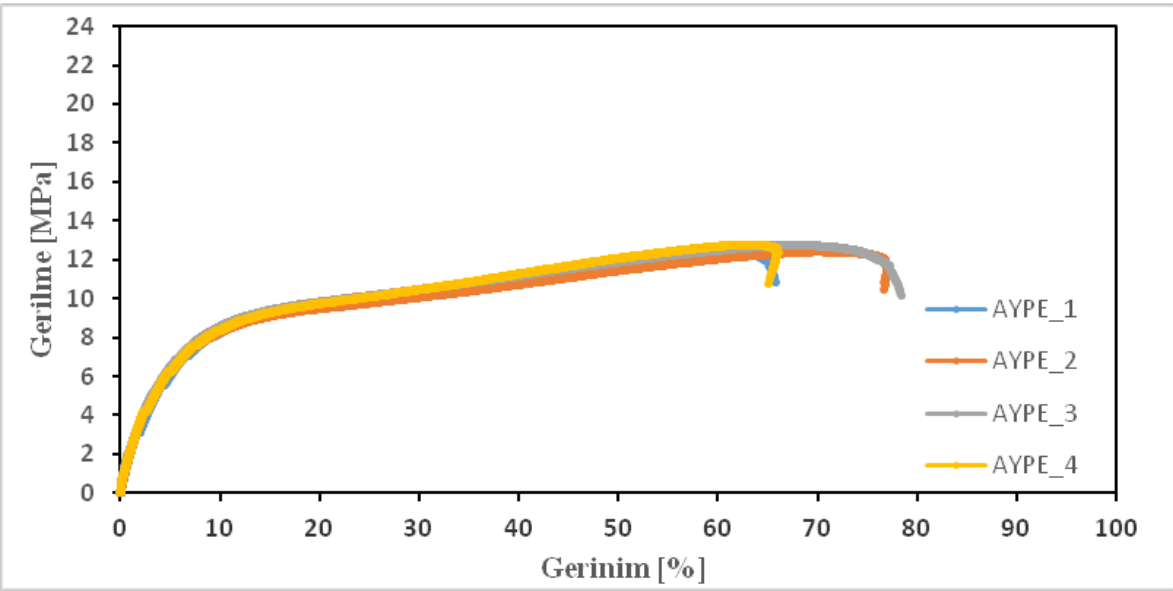

Şekil 8. AYPE numunelerin gerilme-șekil değiștirme davranıșı

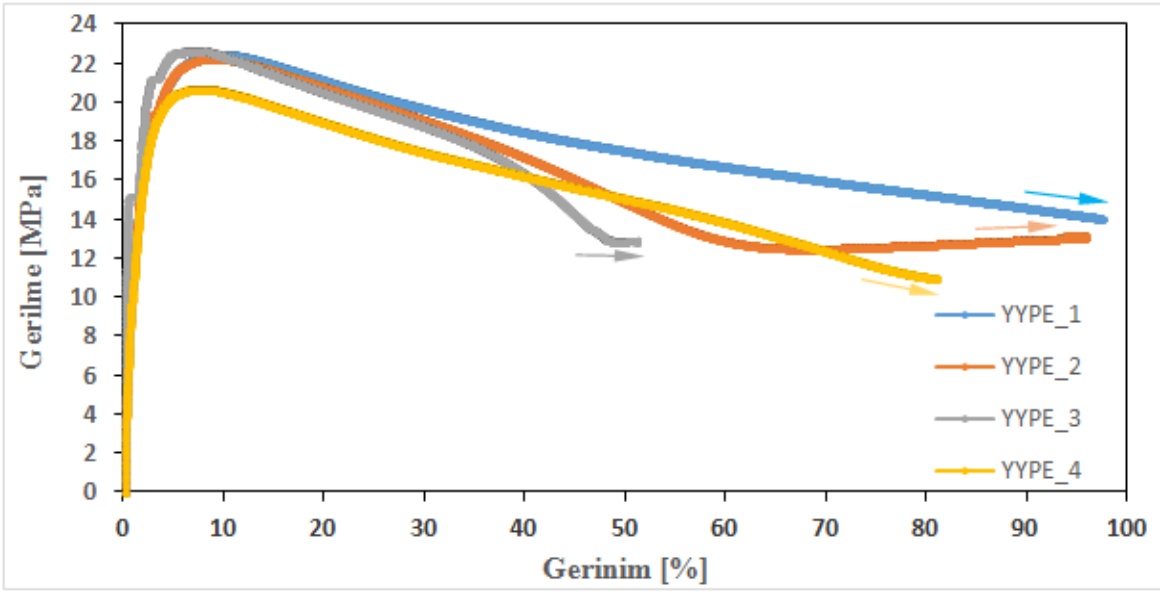

Şekil 9. YYPE numunelerin gerilme-şekil değiştirme davranışı 
DEÜ FMD 22(66), 861-874, 2020

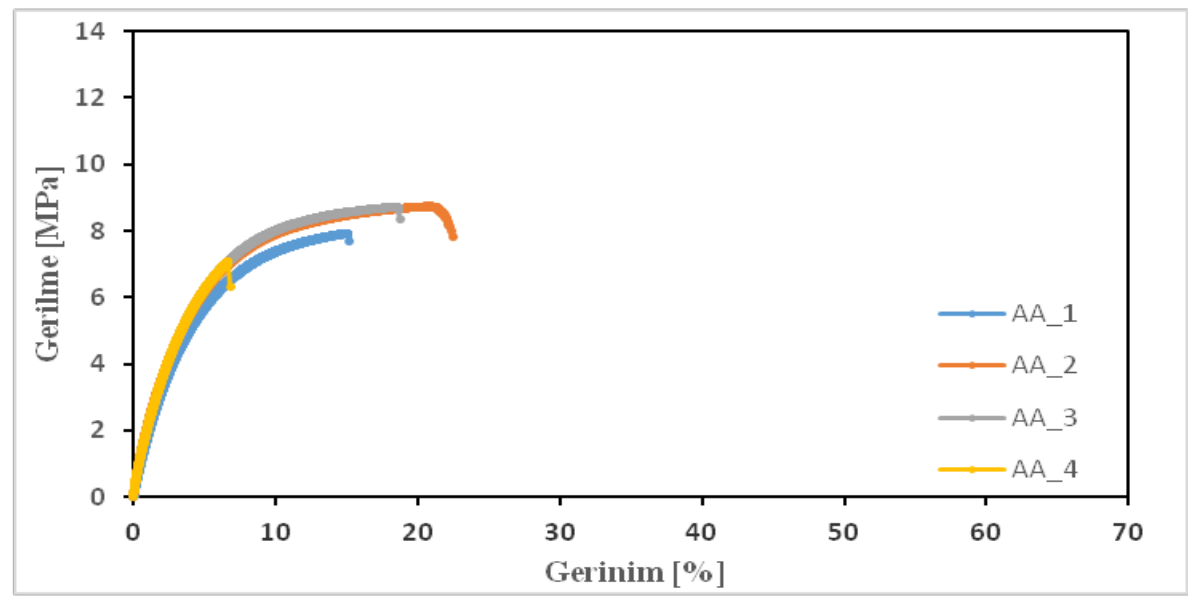

Şekil 10. AA bağlantıların gerilme-șekil değiștirme davranışı

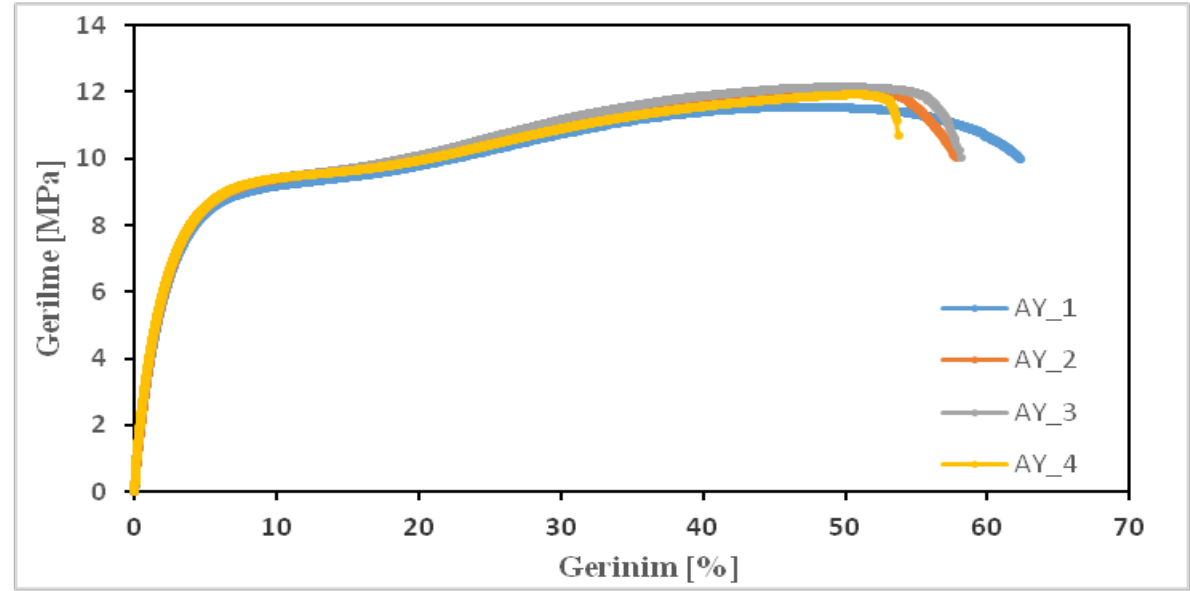

Şekil 11. AY bağlantıların gerilme-şekil değiştirme davranışı

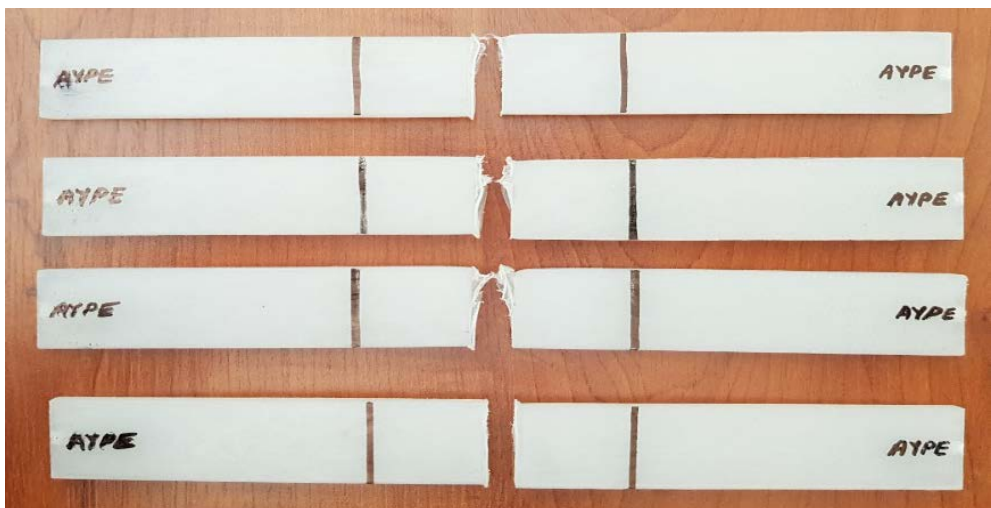

Şekil 12. AA bağlantıların çekme deneyleri sonrası kopma bölgeleri 


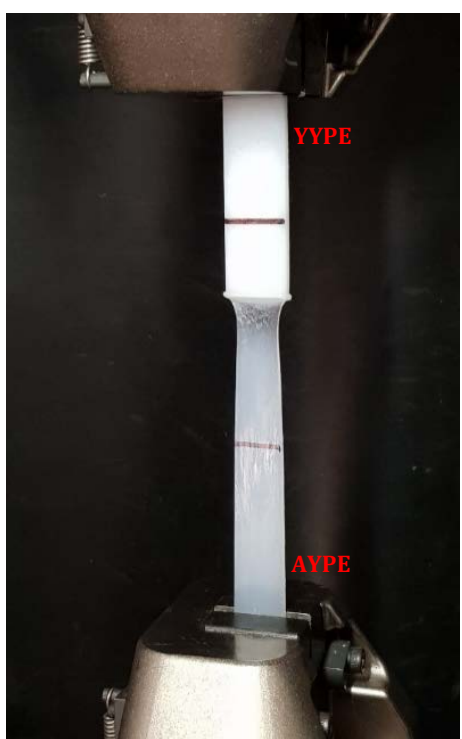

Şekil 13. AY bağlantıların çekme deneyleri esnasındaki şekil değişim görüntüsü

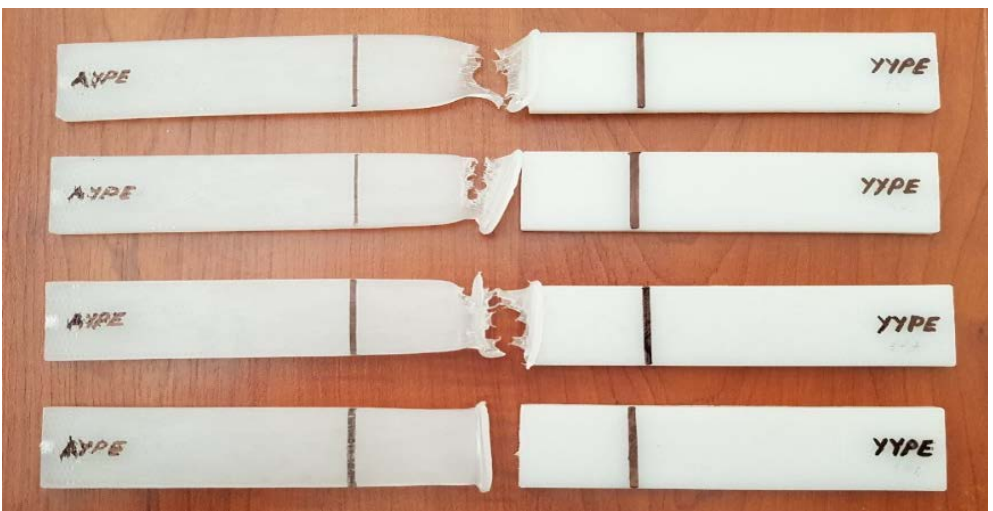

Şekil 14. AY bağlantıların çekme deneyleri sonrası hasar bölgeleri

Deney sonuçları SPK sonrası AA bağlantılarda, maksimum çekme mukavemeti açısından \%64.37'lik bir kaynak verimliliği olduğunu göstermektedir. Numuneler kaynak bölgesinden hasara uğradıkları için ana malzemeye (AYPE) göre birim şekil değiștirme değerleri düşüktür. Benzer bağlantıların söz konusu çekme dayanım özellikleri, AYPE malzemeler YYPE malzemeler ile birleştirilerek maksimum çekme mukavemeti açısından \%94.60 ve maksimum gerilme değeri altında şekil değiştirme açısından \%75.06'ya çıkarılmıştır. Bu sonuçlar benzer olmayan polietilen siniflarının SPK yöntemi kullanılarak daha üstün mekanik özellikler ile başarılı bir şekilde kaynaklanabilirliğini ispat etmektedir. Tablo 5
$A A$ ve AY bağlantıların çekme deneylerine ait sonuçların özetini sunmaktadır.

Kaynaklı bağlantıların verimlilik hesabında AYPE ana malzeme özellikleri göz önünde bulundurularak işlemler gerçekleștirilmiștir. Çalışma kapsamında, her iki bağlantı türünün çekme özellikleri elastisite modülleri (E) açısından da incelenmiştir. AA bağlantılar 184.75 MPa'llk ortalama bir elastisite modülüne sahipken, benzer olmayan bağlantıların elastisite modül değeri $415.70 \mathrm{MPa}$ olarak belirlenmiştir. Elastisite modül değeri malzemelerin karakteristik bir özelliği ve mukavemetinin bir ölçüsü olarak düşünüldügünde, $\quad \mathrm{AY}$ bağlantıların $\mathrm{AA}$ bağlantılara göre çekme dayanımının daha üstün olduğu bir kez daha gösterilmiştir. 
DEÜ FMD 22(66), 861-874, 2020

Tablo 5. Benzer ve benzer olmayan polietilen bağlantıların çekme deneyi sonuçları

\begin{tabular}{lcccccc}
\hline Bağlantı & 1 & 2 & 3 & 4 & Ortalama Değer \\
\hline $\mathbf{A A}$ & $\begin{array}{c}\text { Azami } \\
\text { Ceekme Mukavemeti } \\
\text { (MPa) }\end{array}$ & 7.91 & 8.73 & 8.72 & 7.07 & $\mathbf{8 . 1 1}$ \\
& $\begin{array}{c}\text { Azami Gerilme Altında } \\
\text { Boyca Uzama } \\
(\%)\end{array}$ & 14.92 & 20.80 & 18.60 & 6.64 & $\mathbf{1 5 . 2 4}$ \\
$\mathbf{A Y}$ & 11.54 & 12.06 & 12.14 & 11.92 & $\mathbf{1 1 . 9 2}$ \\
$\quad \begin{array}{c}\text { Azami } \\
\text { Çekme Mukavemeti } \\
\text { (MPa) } \\
\text { Azami Gerilme Altında } \\
\text { Boyca Uzama } \\
\text { (\%) }\end{array}$ & 46.84 & 49.47 & 49.63 & 51.00 & $\mathbf{4 9 . 2 4}$ \\
\hline
\end{tabular}

\section{2. Çentiksiz çarpma dayanımı}

SPK tekniği ile birleștirilmiș benzer ve benzer olmayan polietilen bağlantıların çarpma dayanımını ve çarpma enerjisini belirlemek için, ana malzemeler ve her bir bağlantı çeşidi için 4 adet test gerçekleştirilmiştir. Sonrasında elde edilen sonuçlar incelenmiș ve karșlaștırılmıștır. Buna göre, ana malzemelerde beklenildiği gibi $[39,40]$ bir hasar (parçalanma) gözlemlenmemiş ancak testler esnasında örneklerde absorbe edilen enerji miktarları kayıt altına alınarak ortalamaları hesaplanmıştır. Çarpma dayanımları da, emilen enerji değerleri numune kalınlıklarına bölünerek elde edilmiștir. Izod çarpma deney sonuçları, absorbe edilen enerjiler ve çarpma dayanımları açısından sırasıyla Şekil 15 ve Şekil 16 'da görülebilir. Sonuçlara göre, YYPE ana malzemelerin AYPE malzemelere göre daha yüksek enerji soğurduğu ve dolayısıyla oda sıcaklığında daha iyi çarpma dayanımı gösterdiği tespit edilmiştir [41,42].
Kaynaklı numuneler ana malzemeler ve kendi aralarında karşılaştırıldığında, AA ve AY bağlantıların, numuneler hasara uğrasın veya uğramasın her iki ana malzemeden daha fazla enerji absorbe ettiği belirlenmiştir. Bu noktada, AA bağlantılarda iki numune ve AY bağlantılarda bir numune kaynak bölgesinden hasara uğramış; diğer örneklerde parçalanma (kopma) görülmemiștir. Öte yandan, AY bağlantılarda AA bağlantılara göre \%57.41 oranında daha fazla enerji emilimi olduğu açıça görülmektedir. Kaynaklı bağlantıların çekme dayanım özelliklerine benzer şekilde, AYPE malzemeler YYPE malzemeler ile güvenli biçimde birleştirilerek benzer bağlantılara göre çarpma anında emilen enerji değerlerinde ciddi ölçüde artış sağlanmıștır. 
DEÜ FMD 22(66), 861-874, 2020

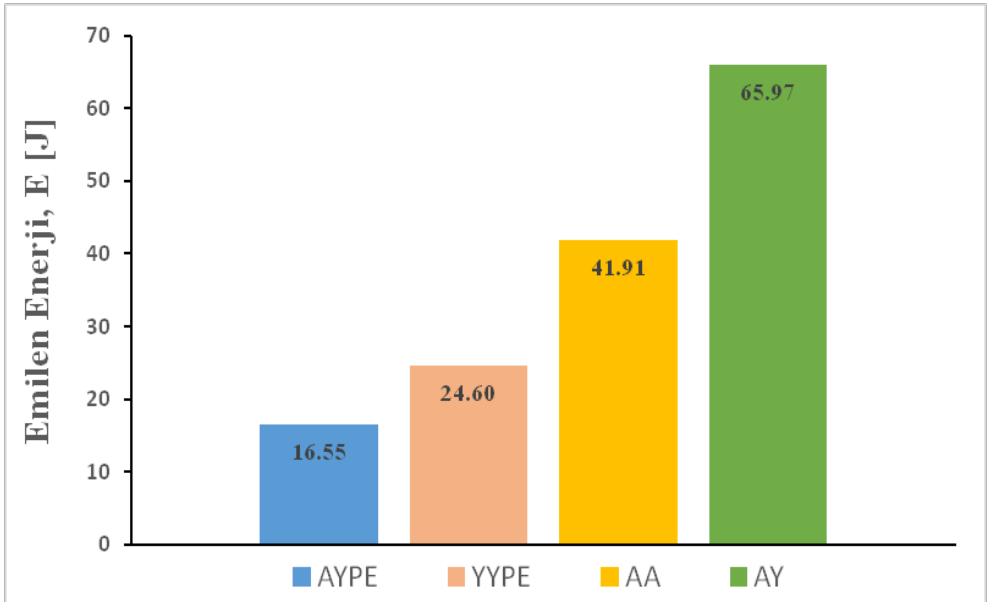

Şekil 15. Çarpma davranışlarının absorbe edilen enerjiler yönünden karşılaștırılması

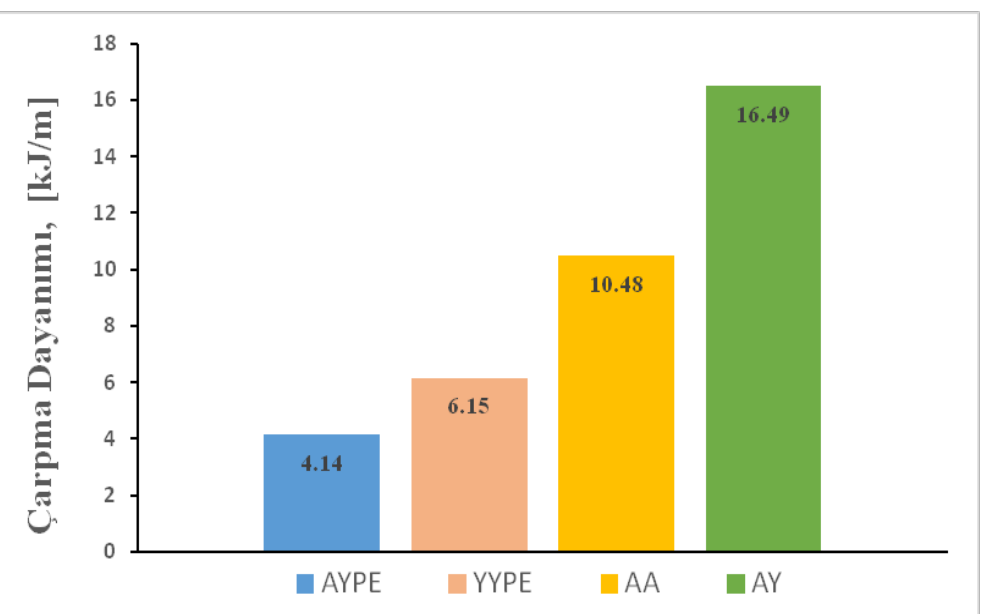

Şekil 16. Çarpma davranışlarının çarpma dayanımları yönünden karşılaștırılması

\subsection{Kırılma yüzeyi incelemesi}

Çekme deneyleri sonrası kaynak bölgesinden hasara uğrayan bağlantıların kırılma yüzeyleri, kaynak bölgesinin mekanik davranışını ve malzeme tepkisini belirleyebilmek için taramalı elektron mikroskobu (JEOL JSM-6060) altında incelenmiştir. Şekil 17-18 söz konusu bağlantıların kırılma yüzeylerine ait resimleri göstermektedir. Buna göre, çekme testi sonrası hasara uğrayan AY bağlantı YYPE numune yüzeyinin (Şekil 17(a)), yüksek süneklik göstergesi olan çok sayıda gerili lifçiklerden (stretched fibrils) oluştuğu belirlenmiştir. Bu lifçikler (fibrils) işlem esnasında önemli miktarda enerji harcandığını ifade etmektedir [43]. Aynı örneğin AYPE numune tarafı (Şekil $17(b)$ ) ise çatlaklı tabaka (blocky structure) șeklinde [44], girinti ve oluklardan oluşan süreksiz bir kırılma yüzeyine sahiptir. Öte yandan AA bağlantıda ise, her iki numune kırılma yüzeyleri (Şekil 18), uzun gerili lifçikler yerine yer yer nokta şeklinde ince lifçikler (point-like fibrils) içeren gevrek kırılma yüzeyi biçiminde karakterize edilebilir. Bu durum, AY bağlantıların çekme testleri sonucu elde edilen daha yüksek mukavemet ve uzama özellikleri ile uyum göstermektedir. 


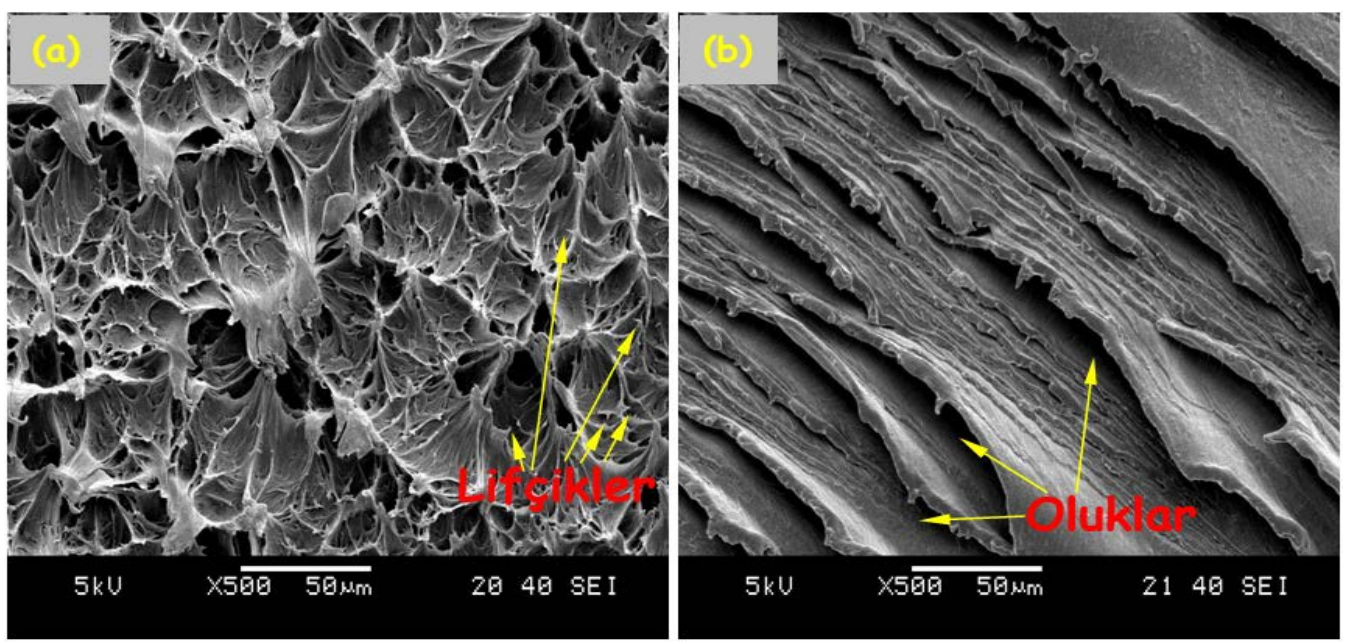

Şekil 17. Çekme testi sonrası AY bağlantı taramalı elektron fotoğrafları: (a) YYPE numune yüzeyi (b) AYPE numune yüzeyi
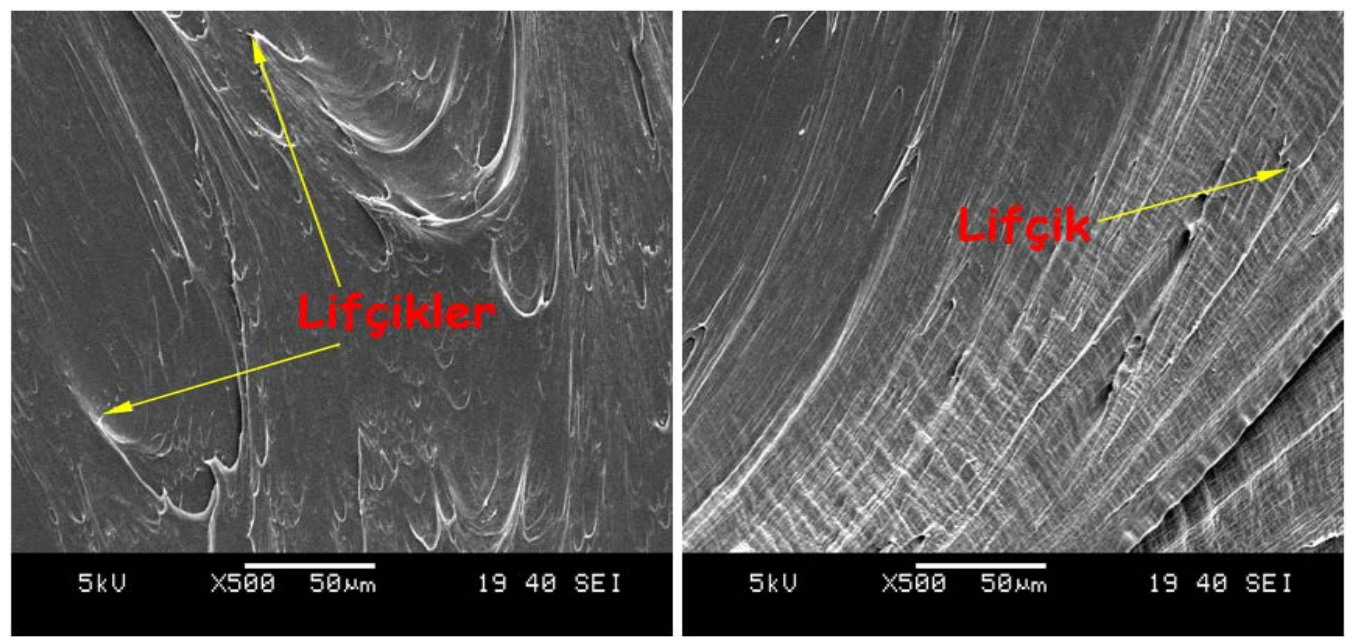

Şekil 18. Çekme testi sonrası AA bağlantı taramalı elektron fotoğrafları

\section{Sonuçlar}

Çalıșma kapsamında benzer ve farklı polietilen sınıfları SPK tekniği kullanılarak birleştirilmiş, bağlantıların mekanik özellikleri deneysel olarak belirlenmiş ve bulgular ana malzemeler ve bağlantıların kendi arasında karşılaştırmalı olarak değerlendirilmiştir. Sonuç olarak, AYPE malzemeler YYPE ile başarılı biçimde birleştirildiğinde, maksimum çekme mukavemeti ve maksimum gerilme altında șekil değiștirme özelliklerinin benzer AYPE bağlantılar ile karșılaștırıldığında önemli ölçüde arttığı saptanmıştır. Bu bağlantıların çekme testlerinde benzer AYPE bağlantıların aksine kaynak bölgesi dışından (ana malzemeden) hasara uğrama eğiliminde oldukları görülmüştür. Çekme deneyleri sonrası incelenen kırılma yüzeylerinde benzer olmayan AYPE-YYPE bağlantılar için, benzer AYPE bağlantılarda rastlanan gevrek kırılma göstergesi olan ince lifçikler yerine, yüksek süneklik işareti olan gerili lifçikler gözlemlenmiştir. Ayrıca elde edilen sonuçlara göre, AYPE malzemelerin YYPE ile birleştirildiklerinde benzer bağlantılara göre daha fazla enerji emilimi gösterdikleri belirlenmiștir. 


\section{Kaynakça}

[1] Kiszka, A., Lomozik, M. 2013. Vibration welding of high density polyethylene HDPE - purpose, application, welding technology and quality of joints, Kovove Materialy, Cilt. 51, s. 63-70. DOI: 10.4149/km_2013_1_63

[2] Amanat, N., James, N.L., McKenzie, D.R. 2010. Welding methods for joining thermoplastic polymers for the hermeticenclosure of medical devices, Medical Engineering \& Physics, Cilt. 32, s. 690-699. DOI: 10.1016/j.medengphy.2010.04.011

[3] Mubarak, Y.A., Abdulsamad, R.T. 2019. Thermal properties and degradability of low density polyethylene microcrystalline cellulose composites, Journal of Thermoplastic Composite Materials, Cilt. 32, s. 487-500. DOI: $10.1177 / 0892705718766387$

[4] Moreno-Moreno, M., Romero, Y.M., Zambrano, H.R Restrepo-Zapata, N.C., Afonso, C.R.M., Unfried-Silgado, J. 2018. Mechanical and thermal properties of friction-stir welded joints of high density polyethylene using a nonrotational shoulder tool, The International Journal of Advanced Manufacturing Technology, Cilt. 97, s. 24892499. DOI: $10.1007 / \mathrm{s} 00170-018-2102-y$

[5] Rojas, K., Canales, D., Amigo, N., Montoille, L., Cament, A., Rivas, L.M., Gil-Castell, O., Reyes, P., Ulloa, M.T., RibesGreus, A., Zapata, P.A. 2019. Effective antimicrobial materials based on low-density polyethylene (LDPE) with zinc oxide ( $\mathrm{ZnO}$ ) nanoparticles, Composites Part B, Cilt. 172, s. 173-178. DOI: 10.1016/j.compositesb.2019.05.054

[6] Charitos, I., Georgousis, G., Kontou, E. 2019. Preparation and Thermomechanical Characterization of Metallocene Linear Low-Density Polyethylene/Carbon Nanotube Nanocomposites, Polymer Composites, Cilt. 40, s. E1263-E1273. DOI: 10.1002/pc.24961

[7] Liang, J-Z. 2019. Melt spinning flow behaviour of highdensity polyethylene blended with low-density polyethylene, Plastics, Rubber and Composites, Cilt. 48, s. 256-262. DOI: 10.1080/14658011.2019.1603026

[8] Siddique, S., Smith, G.D., Yates, K., Mishra, A.K., Matthews, K., Csetenyi, L.J., Njuguna, J. 2019. Structural and thermal degradation behaviour of reclaimed clay nano-reinforced low-density polyethylene nanocomposites, Journal of Polymer Research, Cilt. 26, s. 1-14. DOI: $10.1007 / \mathrm{s} 10965-019-1802-9$

[9] Zia, J., Paul, U.C., Heredia-Guerrero, J.A., Athanassiou, A., Fragouli, D. 2019. Low-density polyethylene/curcumin melt extruded composites with enhanced water vapor barrier and antioxidant properties for active food packaging, Polymer, Cilt. 175, s. 137-145. DOI: 10.1016/j.polymer.2019.05.012

[10] Chavan, S., Gumtapure, V., Peruma, D.A. 2019. Characterization of linear low-density polyethylene with graphene as thermal energy storage material, Materials Research Express, Cilt. 6, 065511. DOI: 10.1088/20531591/ab0e36

[11] Azizi, S., Ouellet-Plamondon, C.M., Nguyen-Tri, P., Fréchette, M., David, E. 2019. Electrical, thermal and rheological properties of low-density polyethylene/ethylene vinyl acetate/graphene-like composite, Composites Part B, Cilt. 177, 107288. DOI: 10.1016/j.compositesb.2019.107288

[12] Sabet, M., Soleimani, H. 2019. Broad studies of graphene and low-density polyethylene composites, Journal of Elastomers \& Plastics, Cilt. 51, s. 527-561. DOI: $10.1177 / 0095244318802608$

[13] Guichard, B., Cassagnau, P., Sudre, G., Fulchiron, R., Ledieu, B., Espuche, E. 2019. Effect of a Post-Annealing Process on Microstructure and Mechanical Properties of High-Density Polyethylene/Silica Nanocomposites, Journal of Polymer Science, Part B: Polymer Physics, Cilt. 57, s. 535-546. DOI: 10.1002/polb.24809

[14] Zhang, Q., Khan, M.U., Lin, X., Cai, H., Lei, H. 2019. Temperature varied biochar as a reinforcing filler for high-density polyethylene composites, Composites Part B, Cilt. 175, 107151. DOI: 10.1016/j.compositesb.2019.107151

[15] Durmus, A., Ercan, N., Alanalp, M.B., Gökkurt, T., Aydin, I. 2019. Effects of Liquid Crystal Polymer and Organoclay Addition onthe Physical Properties of HighDensity Polyethylene Films, Polymer Engineering and Science, Cilt. 59, s. 1344-1353. DOI: 10.1002/pen.25117

[16] Fairbrother, A., Hsueh, H-C., Kim, J.H., Jacobs, D., Perry, L., Goodwin, D., White, C., Watson, S., Sung, L-P. 2019. Temperature and light intensity effects on photodegradation of high-density polyethylene, Polymer Degradation and Stability, Cilt. 165 , s. $153-160$. DOI: 10.1016/j.polymdegradstab.2019.05.002

[17] Liu, Y., Shao, X., Huang, J., Li, H. 2019. Flame sprayed environmentally friendly high density polyethylene (HDPE)-capsaicin composite coatings for marine antifouling applications, Materials Letters, Cilt. 238, s. 4650. DOI: 10.1016/j.matlet.2018.11.144

[18] Zhang, Q., Cai, H., Ren, X., Kong, L., Liu, J., Jiang, X. 2017. The Dynamic Mechanical Analysis of Highly Filled Rice Husk Biochar/High-Density Polyethylene Composites, Polymers, Cilt. 9, 628, s. 1-10. DOI: $10.3390 /$ polym 9110628

[19] Bucknall, C.B., Drinkwater, I.C., Smith, G.R. 1980. Hot plate welding of plastics: Factors affecting weld strength, Polymer Engineerıng and Science, Cilt. 20, s. 432-440. DOI: $10.1002 /$ pen.760200609

[20] Yousefpour, A., Hojjati, M., Immarigeon, J-P. 2004. Fusion Bonding/Welding of Thermoplastic Composites, Journal of Thermoplastic Composite Materials, Cilt. 17, s. 303-341. DOI: 10.1177/0892705704045187

[21] Friedrich, N., Hoffschlag, R., Schöppner, V., Schnieders, J., Gövert, S. 2012. Cycle Time Reduction by Forced Air Cooling For Hot Plate Welding, Welding in The World, Cilt. 56, s. 101-107. DOI: 10.1007/BF03321340

[22] da Costa, A.P., Botelho, E.C., Costa, M.L., Narita, N.E., Tarpani, J.R. 2012. A Review of Welding Technologies for Thermoplastic Composites in Aerospace Applications, Journal of Aerospace Technology and Management, Cilt. 4, s. 255-265. DOI: 10.5028/jatm.2012.04033912

[23] Birley, A.W., Buxton, R. 1989. The hot plate welding of high-density polyethylene, Polymer Testing, Cilt. 8, s. 277-287. DOI: 10.1016/0142-9418(88)90029-3 


\section{DEÜ FMD 22(66), 861-874, 2020}

[24] Ülker, A., Kocatüfek, U.E., Sayer, S., Yeni, C. 2015. Application of the Taguchi method for the optimization of the strength of polyamide 6 composite hot plate welds Materials Testing, Cilt. 57, s. 531-542. DOI: $10.3139 / 120.110741$

[25] Tariq, F., Naz, N., Khan, M.A., Baloch, R.A. 2012 Failure Analysis of High Density Polyethylene Butt Weld Joint, Journal of Failure Analysis and Prevention, Cilt. 12, s. 168-180. DOI: $10.1007 / \mathrm{s} 11668-011-9536-y$

[26] Nonhof, C.J. 1996. Optimization of Hot Plate Welding for Series and Mass Production, Polymer Engineering and Science, Cilt. 36, s. 1184-1195. DOI: 10.1002/pen.10512

[27] Nieh, J-Y., Lee, L.J. 1998. Hot Plate Welding of Polypropylene. Part I: Crystallization Kinetics, Polymer Engineering and Science, Cilt. 38, s. 1121-1132. DOI: $10.1002 /$ pen.10279

[28] Nieh, J-Y., Ni, J., Lee, L.J. 1998. Hot plate welding of polypropylene. Part II: Process simulation, Polymer Engineering and Science, Cilt. 38, s. 1133-1141. DOI: $10.1002 /$ pen. 10280

[29] Oliveira, M.J., Bernardo, C.A., Hemsley, D.A. 2001. Morphology and mechanical behavior of polypropylene hot plate welds, Polymer Engineering and Science, Cilt. 41, s. 1913-1922. DOI: $10.1002 /$ pen.10888

[30] Taşkıran, E., Sayer, S., Özes, Ç., Yeni, Ç., Ülker, A 2015. Effect of process parameters and talc ratio on hot plate welding of polypropylene, Materialwissenschaft und Werkstofftechnik, Cilt. 46, s. 860-872. DOI: 10.1002 /mawe.201500438

[31] Stokes, V.K. 1998. Experiments on the hot-tool welding of three dissimilar thermoplastics, Polymer, Cilt 39, s. 2469-2477. DOI: 10.1016/S0032-3861(97)00569-7

[32] TS EN ISO 294-1(2018): Plastikler - Termoplastik malzemelerden enjeksiyon kalıplama ile deney parçalarının hazırlanması - Bölüm 1: Genel prensipler ve çok amaçlı çubuk deney parçalarının kalıplanması.

[33] Ehrenstein, G.W. 2004. Handbuch KunststoffVerbindungstechnik. Hanser. München, 710s.

[34]https://app.petkim.com.tr/web/urun/File.ashx?fn=U R.12-BF-U1213\&l=tr\&fl=urunler (Erişim Tarihi: 13.12.2019).

[35]https://app.petkim.com.tr/web/urun/File.ashx?fn=U R.15-BF-U40203\&l=tr\&fl=urunler (Erişim Tarihi: 13.12.2019)

[36] TS EN 12814-2(2003): Yarı mamul termoplastik malzemeler-Kaynaklı bağlantı deneyleri-Bölüm 2: Cekme deneyi.

[37] Mahmoud, M.E., El-Khatib, A.M., El-Sharkawy, R.M., Rashad, A.R., Badawi, M.S., Gepreel, M.A. 2019. Design and testing of high-density polyethylene nanocomposites filled with lead oxide micro- and nano-particles: Mechanical, thermal, and morphological properties, Journal of Applied Polymer Science, Cilt. 136, 47812, s. 1 11. DOI: $10.1002 /$ app.47812

[38] Addiego, F., Martino, J.D., Ruch, D., Dahoun, A Godard, O., Patlazhan, S. 2011. Quantification of Cavitation in Neat and Calcium Carbonate-Filled High-
Density Polyethylene Subjected to Tension, Journal of Engineering Materials and Technology, Cilt. 133, 030904, s. 1-7. DOI: $10.1115 / 1.4004046$

[39] Lushcheikin, G.A. 2017. Modelling the impact strength of polymeric materials, International Polymer Science and Technology, Cilt. 44, s. 27-32. DOI: 10.1177/0307174X1704401006

[40] https://www.curbellplastics.com/ResearchSolutions/Plastic-Properties/HDPE-vs-LDPE (Erișim Tarihi: 24.01.2020).

[41] Nishimura, H., Narisawa, I. 1991. Evaluation of impact properties of butt-fusion-jointed medium-density polyethylene pipes for gas distribution, Polymer, Cilt. 32, s. 2199-2204. DOI: 10.1016/0032-3861(91)90046-L

[42] http://www.sdplastics.com/polyeth.html (Erişim Tarihi: 24.01 .2020 )

[43] Singh, G., Bhunia, H., Rajor, A., Choudhary, V. 2011. Thermal properties and degradation characteristics of polylactide, linear low density polyethylene, and their blends, Polymer Bulletin, Cilt. 66, s. 939-953. DOI: 10.1007/s00289-010-0367-X

[44] Brough, I., Haward, R.N., Healey, G., Wood, A. 2004. Scanning electron micrographs of high density polyethylene fracture surfaces, Polymer, Cilt. 45, s. 31153123. DOI:10.1016/j.polymer.2004.02.036 